\title{
Research Paper: Examination of Postural Control of Body and the Onset Time of Electrical Activity of Selected Ankle Muscles During Single-leg Landing in Subjects With Pronated and Normal Foot
}

\author{
Fatemeh Kolasangiani $^{1^{*}}$ (D), Zahed Mantashloo² ${ }^{\text {(D) }}$, Shahin Salehi ${ }^{3}$ (D), Mohsen Moradi ${ }^{2}$ (D)
}

1. Department of Physical Education and Sports Science, Faculty of Physical Education and Sports Sciences, Kharazmi University, Tehran, Iran 2. Department of Sports Injury and Biomechanics, Faculty of Physical Education and Sports Sciences, Kharazmi University, Tehran, Iran.

3. Department of Sport Medicine, Faculty of Imam Hossein Educational Hospital, Shahid Beheshti University of Medical Sciences, Tehran, Iran.

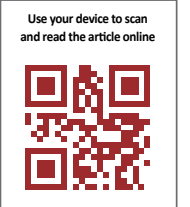

Citation: Kolasangiani F, Mantashloo Z, Salehi Sh, Moradi M. Examination of Postural Control of Body and the Onset Time of Electrical Activity of Selected Ankle Muscles During Single-leg Landing in Subjects With Pronated and Normal Foot. Journal of Modern Rehabilitation. 2019; 13(2):79-86. http://dx.doi.org/10.32598/JMR.13.2.79

\section{(i) (8)}

Article info:

Received: 25 Jun 2018

Accepted: 20 Aug 2018

Available Online: 01 Apr 2019

\section{Keywords:}

Pronation, Postural control, Muscles activity, Landing, Men

\section{ABSTRACT}

Introduction: This study aimed to explore foot pronation deformity on the postural control of the body and the onset time of the electrical activity of ankle muscles during landing.

Materials and Methods: In this cross-sectional study, 27 people with a pronated foot deformity and 27 normal people participated. The force plate was used to measure the postural control of the body. Surface electromyography signals were recorded in landing tests with electromyography, which synchronized with a force plate. To compare the performance of the two groups, we used multivariate analysis of variance.

Results: The results indicated a statistically significant difference in the medial-lateral direction of differences between center of pressure and center of mass (COP-COM) between foot pronation (pronated) and normal group during landing $(\mathrm{P}<0.05)$. Regarding the variable of the onset time of the muscular electrical activity during landing, there was a statistically significant difference in medial gastrocnemius, soleus, tibialis anterior, and peroneus longus muscles between the two groups $(\mathrm{P}<0.001)$.

Conclusion: Foot pronation can be regarded as a factor affecting the biomechanics of landing by changing postural control of the body in the medial-lateral direction and the onset time of the electrical activity of medial gastrocnemius, soleus, tibialis anterior, and peroneus longus muscles during landing movement.

* Corresponding Author:

Fatemeh Kolasangiani, MSc.

Address: Department of Physical Education and Sports Science, Faculty of Physical Education and Sports Sciences, Kharazmi University, Tehran, Iran. Tel: +98 (936) 3446672

E-mail:fateme_ghezal@gmail.com 


\section{Introduction}

F

oot pronation involves the loss of the medial longitudinal arch of the foot, which causes the navicular drop down and is accompanied by other anatomical anomalies [1,2]. The reduction of longitudinal arch height depends on the condition of the bones and ligaments of the foot, leg, and foot muscles, and plays an essential role in maintaining balance and performing motor abilities and skills [3]. People with pronated foot suffer from many biomechanical inefficiencies in ankle and foot [4]. Foot pronation can result in biomechanical irregularities in the performance that may lead to the Achilles tendon pain, leg pain, hamstring stretch, quadriceps stretch, and so on [5]. Thus, pronated foot leads to the impairment in postural control, the disorder in pressure exerting foot, risk of lower extremity injuries, and changes in the mobility of ankle and foot joints [6-9], which may secondarily alter muscular activity [10]. Therefore, these disorders, besides changes in the standing position, influence the displacement.

In many sports such as basketball, volleyball, and handball, single- and double-leg landing motions are very common [11]. Although during walking and running, the force from the ground (ground reaction force) reaches the lower limb up to 1.5 and 2.5 times the body weight, respectively [12], in a landing motion from a height, this force can reach 7 times the bodyweight [13]. This pressure can add a double load on the joints and the lower extremities - besides, the risk of losing balance and falling during the exercise increases [14].

The displacement of the center of pressure as the stature postural stability index provides useful information for foot performance because of the predicting indicator of dynamic balance [15]. Most studies about people's stability in foot pronation deformity have been conducted in a standing position [16]. Colby et al. stated that the standing position does not effectively challenge the neuromuscular system in sporting activities. Evidence suggests that when musculoskeletal abnormalities occur in one of the joints, muscles on the concave side shorten, and muscles on the convex side elongate $[17,18]$.

As a result, the onset time of muscular activity probably changes compared with the normal people. In this case, other muscles compensate for the dysfunction during sports activities. Therefore, the slightest biomechanical change at the level of reliance affects the postural control of body and balance [19]. Since previous studies have mostly examined static balance [16] and the electrical activity of muscles during walking and running [20-23], it seems necessary to investigate the postural control of the body dynamically, as well as the timing pattern of muscles during functional movements such as landing.

As changes in the foot structure can change in the postural control of the body and muscle timing during jump movements, and since these changes can affect lower extremity joints, knowing these variables can help therapists and coaches choose the right therapeutic and training approach. Therefore, the current study investigates the effect of foot pronation abnormality on the postural control of the body and the onset of the electrical activity of selected ankle muscles during landing motion.

\section{Materials and Methods}

The population of the cross-sectional study includes male students of Physical Education and Sports Science in Karaj City, Iran. Of them, 27 people with a pronated foot deformity and 27 normal people were selected based on the purposive sampling method. The place of the research was the Lab of Kharazmi University, and the data were collected in one week.

The number of the subjects was determined, using the $G \times$ POWER software $(\alpha=0.05$, effect size $=0.70, \beta=0.2$, statistical power $=0.80$ ). Each group contained 27 subjects.

Foot Posture Index (FPI) method was used for dividing the subjects into the pronated and normal groups [22]. Each subject was asked to stand, take a few steps forward, march on the spot for 6 to 8 steps, and stand still with arms by their side and looking forward. During the assessment, it is important to ensure that the patients do not swivel and try to see what is happening on themselves, as this will significantly affect the foot posture. The observers performed the foot assessment of each subject, using 6 criteria of the FPI: 1. Talar head palpation; 2. Curvature at the lateral malleoli; 3. Inversion/ eversion of the calcaneus; 4 . Talonavicular bulging; 5 . Congruence of the medial longitudinal arch; 6 . Abduction/adduction of the forefoot on the rearfoot, where each item is scored between -2 and +2 to give a total between -12 (highly supinated) and +12 (highly pronated) [23]

The subjects were asked to sit on a chair and place their feet in a state of weightlessness. Then, their feet were placed in the natural position of the subtalar joint. One of the researchers put his thumb under the medial malleolus, and the subject rotated the foot in and out slowly so that the researcher's index finger and thumb were placed in the same direction. In this condition, first, navicular tuberosity was marked. Then, the distance from the ground to 
navicular tuberosity was measured with a ruler. Next, the subjects were asked to stand and divide their weight on both feet equally. In this condition, the height of Navicular tuberosity from the ground was measured, too [24].

The subjects were selected based on the inclusion criteria, including general health, male gender, voluntary participation, and the completion of the consent form. The exclusion criteria included a difference in lower extremities, as well as a history of musculoskeletal injuries, especially in the lower extremities. After explaining the ethical considerations of the research and some instructions and training (which did not interfere with the process of research and data collection), the subjects were asked to wear sports clothes. To avoid injuries, before running the test, the subjects were instructed to perform initial warm-up. Then, they completed the informed consent form and personal information questionnaire (age, weight, height, etc.). The height and weight of the subjects were measured, using a metal height gauge (SEKA from Germany) and a digital scale (Germany).

The electrode placement was performed, using the SENIAM (Surface ElectroMyoGraphy for the NonInvasive Assessment of Muscles) protocol [24]. The SENIAM method determines precisely where the electrodes $(\mathrm{Al} / \mathrm{AgCl})$ are placed on the muscle. Using the method, we placed the electrodes on medial gastrocnemius, soleus, tibialis anterior, and peroneus longus muscles (Figure 1). The electrode for the medial gastrocnemius was placed over the bulge of the medial head of the gastrocnemius. The soleus electrode was just put medial to the Achilles tendon, inferior to the midpoint of the lower leg. Electrode placement on the tibialis anterior was at $1 / 3$ on the line $1 \mathrm{~cm}$ to $2 \mathrm{~cm}$ lateral to the tibia. Electrode placement on the tibialis anterior was at $25 \%$ of the line between the tip of the head of the fibula and the tip of the lateral malleolus, both on the affected and unaffected sides [24]. When the electrode placement process was completed, the subjects were asked to run a few steps in the lab to identify and resolve any possible restrictions that may be caused by the electrodes for the subjects.

To obtain changes in the Center of Pressure (COP)mass in landing movement, a force plate (Bertec Model, the USA) was used. The sampling frequency of the force plate was $500 \mathrm{~Hz}$, and its sensitivity was lower than $1 \mathrm{~N}$. Then, the subjects landed on the force plate from a 48.8$\mathrm{cm}$ high box placed next to the force plate in a controlled single-leg way. Each subject practiced landing 3 times. Then, each subject performed 5 landing movements and tried to maintain their balance. The rest interval between the tests was 2 minutes [25].

Differences in the Center of Mass (COM) to body pressure in the anterior-posterior and medial-lateral directions were calculated, using Winter inverted pendulum formula [23] (Formula 1):

1. $C O P-C O M=I \times C O ̈ M / W h I A-P=0.0533 \times m \times H 2$ and $I M-L=0.0572 \times m \times H$

In this formula, I stands for inertia torque around the ankle joint, $\mathrm{H}$ (meter) is the height of the person and $\mathrm{m}$ (kilogram) is body mass, CÖM is the acceleration of the center of mass (in 2 directions of medial-lateral and anterior-posterior), $\mathrm{W}$ (newton) is the weight, and $\mathrm{h}$ (meter) is the height [26]. As the center of pressure and the center of mass are measured entirely independently, the correlation of the equation (COP-COM) with the CÖM measure of the validity of the model has been simplified [26]. The average correlation in the anterior-posterior and medial-lateral directions has been reported as 0.94 [26].

Recording the surface electromyography signals in the tests of Maximal Voluntary Contraction (MVC) and landing motion was implemented with electromyography (MEI model, The United Kingdom), synchronized with a force plate.

To reduce the cross-talk, we used small electrodes and the distance between the electrodes was as small as possible and the electrodes arranged parallel to the main muscle bulk. Also, to prevent the cross-talk around tibialis anterior and peroneus longus, the tibialis anterior electrode was put in parallel with the fibula.

\section{Results}

Table 1 presents the Mean $\pm \mathrm{SD}$, as well as the demographics of the subjects, including age, height, weight, navicular drop, and FPI. The groups were matched regarding their age, height, and weight. Similarly, the median FPI in the normal group is 3 , which is in the normal range ( $0-5$ score). The median FPI in the pronated foot group is 8 , and as it is more than 5 , it is considered part of the pronated foot [22]. The difference in FPI between the two groups is statistically significant $(\mathrm{P}<0.001)$.

According to the normality of the data and the homogeneity of variance, MANOVA was used to compare the groups. Table 2 presents the results of MANOVA related to the variable of the differences in the center of 


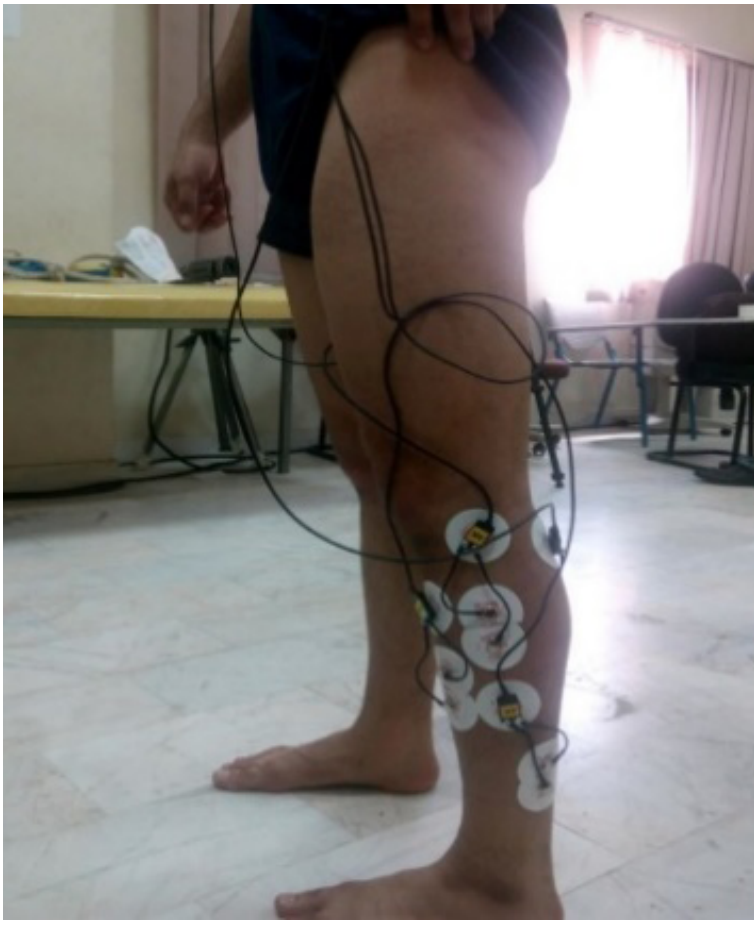

$J \mathrm{MR}$

Figure 1. Electrode placement on the desired muscles, using the SENIAM (Surface ElectroMyoGraphy for the Non-Invasive Assessment of Muscles) method

pressure-mass. There is no statistically significant difference in changes in the center of the pressure-mass variable in anterior-posterior direction during landing motion between the normal and pronated groups $(\mathrm{P}=0.205)$, while a statistically significant difference is observed in medial-lateral direction $(\mathrm{P}<0.001)$.

Also, the statistical results related to the comparison of the electrical activity of the selected muscles of ankle between the normal and pronated foot groups in Table 3 indicate a significant difference in the variable of the electrical activity of muscle between the two groups during landing motion in medial gastrocnemius muscles $(\mathrm{P}<0.001)$, soleus $(\mathrm{P}<0.001)$, tibialis anterior $(\mathrm{P}<0.001)$, and peroneus muscles $(\mathrm{P}<0.001)$.

Table 1. Mean \pm SD of age, height, weight, and median of FPI

\section{Discussion}

The present study aimed to examine the effect of foot pronation deformity on the postural control of the body and the electrical activity of the selected muscles of the ankle in landing. As the results demonstrated, there was no statistically significant difference in the center of pressure-mass in the anterior-posterior direction, but the difference was statistically significant between the groups in the medial-lateral direction. In De et al. study, which examined people with flat feet during gait, the results showed that the displacement of the COP was significantly correlated to the medial arch of the foot [27]. The reason for the discrepancy of this research is likely attributed to the application of changes in the pressure center rather than the pressure-mass center. Similarly, Kim et al. study on people with the flat foot during single-leg balance motion showed that the extent of variations in both directions of anterior-posterior and medial-lateral in people with the flat foot was greater than normal people [16]. And the medial-lateral direction of the study was consistent with the present research result.

The cause of foot pronation is the weakness of the muscles of the medial arch of the foot, especially the tibialis posterior muscle. This muscle passes under the calcaneonavicular ligament. This ligament plays an essential role in the foot since it is located at the top of the longitudinal arch and is regarded as its key. Bodyweight is transferred to the ligament by the talus, and the forces are divided into the front side (the head of metatarsal bone) and the rear side (heel) [28]. As mentioned, the posterior tibialis muscle passes underneath the ligament and, to some extent, contributes to it and reduces its heavy task. When the tibialis posterior muscle grows weak and the feet endure weight force, calcaneonavicular ligament is stretched and cannot support the talus bone because of being loose [28]. As a result, the depended bones on the ligament are slightly displaced, and the power distribution becomes abnormal and the mechanism of the stability of postural control in medial-lateral direction is impaired.

\begin{tabular}{|c|c|c|c|c|c|c|}
\hline \multirow{2}{*}{\multicolumn{2}{|c|}{ Variable }} & \multicolumn{5}{|c|}{ Mean \pm SD } \\
\hline & & Age (y) & Height $(\mathrm{cm})$ & Mass (kg) & FPI (s) & Navicular Drop (mm) \\
\hline \multirow{2}{*}{ Group } & Normal & $22.87 \pm 2.12$ & $178.42 \pm 7.34$ & $79.33 \pm 8.10$ & $3 \pm 1.39$ & $7.82 \pm 0.68$ \\
\hline & Pronation & $23.29 \pm 1.84$ & $175.04 \pm 5.95$ & $78.23 \pm 8.41$ & $8 \pm 1.41$ & $12.66 \pm 1.17$ \\
\hline \multicolumn{2}{|c|}{$P$} & 0.476 & 0.193 & 0.628 & 0.000 & 0.000 \\
\hline
\end{tabular}


Table 2. The results of MANOVA related to the variable of changes in the center of pressure-mass

\begin{tabular}{ccccc}
\hline Variable & Direction & Mean Square & F & P \\
\hline \multirow{2}{*}{ COP-COM } & Anterior-posterior & 0.48 & 1.363 & 0.248 \\
& Medial-lateral & 7.77 & 55.19 & 0.000 \\
\hline
\end{tabular}

Table 3. The results of MANOVA related to the variable of the onset of muscles activity

\begin{tabular}{ccccc}
\hline Variable & Muscle $(\mathbf{m s})$ & Mean Square & F & P \\
\hline & Gastrocnemius & 28153.50 & 261.855 & 0.000 \\
The onset of muscles activity & Soloes & 40398.68 & 372.436 & 0.000 \\
& Tibialis anterior & 9653.40 & 39.396 & 0.000 \\
& Peroneus longus & 34000.46 & 95.966 & 0.000 \\
\hline
\end{tabular}

The results indicated a statistically significant difference in the onset of the muscular activity of medial gastrocnemius muscle, soleus, tibialis anterior, and peroneus longus muscles in landing motion between the normal and pronated feet groups. The pronated foot causes the onset of the gastrocnemius muscle, soleus, and peroneus longus muscles to be delayed, and the onset of the tibialis anterior muscle occurs earlier. In a study, Javdaneh et al. examined the timing of the activity of the anterior cruciate ligament agonist and antagonist muscles in the male athletes with ankle pronation abnormality. They concluded that there was no statistically significant difference in the medial gastrocnemius muscle between the flat and normal feet groups [29]. Also, Gray et al. carried out a study entitled "electromyography and motion analysis for flat and normal feet subjects". They reported no statistically significant difference in the onset of the activity of tibialis anterior and peroneus longus muscles between the flat and normal feet groups [30]. The reason for the inconsistency between these studies and the current study may be related to the difference in the subjects and the performed movements.

Abnormalities in the neuromuscular function of the muscles around the ankle observed in persons with the pronated foot can be attributed to changes in pre-designed programs sent from the central nervous system to the muscles. Changes in the pre-designed programs sent from the central nervous system, which have been observed in this study, can be attributed to the fact that foot pronation in the long-term leads to anomalies in the ankle joint position sense. The deficit of the ankle joint position sense also results in changes in impulse sent from the joint to the nervous system. Modified impulses in the long-term can cause widespread neurophysiologic changes, including changes in motor commands given to the muscles [30].

The pre-designed programs of postural control sent from the central nervous system play an important role in the timely activation of the muscles while performing various activities. The onset of muscle activities before the foot touches the ground, followed by the emergence of pre-feedback muscle, suggests the presence of a central motor control strategy that prepares muscles for attracting contact forces [31]. Delay in the activation of peroneus longus muscle and the earlier activation of the tibialis anterior muscle in the pronated foot group lead to the failure of the co-contraction relationship between two muscles (antagonist muscles of subtalar joint). They can also cause the torque arm of the subtalar joint to invert before the foot touches the ground and expose the joint to the external torsion. The co-contraction of the ankle antagonist muscles increases the stiffness of the joint and prepares it for controlling the rapid and extreme change in the tendon-muscle complex and fast movements when performing various movements.

Delay in the onset of medial gastrocnemius and soleus muscle activities before foot contacts the ground causes a reduction in the amount of pre-feedback muscle activity and, consequently, a decrease in the production of plantar-flexion torque of the ankle-foot complex during ground contact that may cause further damage [31]. 
For normalizing the electromyography data, an MVC test was used. Following a 10-minute rest, the subjects were asked to complete a series of strength tests to capture their MVC for each muscle consistent with Hagen et al. methods. Briefly, this process included performing maximum voluntary isometric contractions against manual resistance in 3-movement directions of plantarflexion (medial gastrocnemius, soleus), dorsiflexion (tibialis anterior), and pronation (peroneus longus) [32].

The device contains transmitter and receiver units. The transmitter unit, which is strapped as a waist belt around the subjects' waist, has 8 channels, and the bandwidth of each channel is $1000 \mathrm{~Hz}$. It can send waves wirelessly through the antenna at a distance up to $100 \mathrm{~m}$ away from the receiver, whose sensitivity is lower than $1 \mathrm{mV}$. Filtering the electromyography data was carried out using the band-pass Butterworth method with a cut-off frequency of 10-500 Hz. The threshold level of the onset of activity was determined when the muscle activity exceeded Mean \pm SD of baseline [33].

The length and width of the foot were used for normalizing the data of changes in the center of pressure-mass. The current study used MATLAB software to analyze data, the Shapiro-Wilk test to assess the normality of the data, the Levene's test for the equality of error variances, and Multivariate Analysis of Variance (MANOVA) $(\mathrm{P} \leq 0.05)$ to compare the groups' data.The average navicular drop in the normal group is $7.82 \mathrm{~mm}$, which is in the normal range $(5-9 \mathrm{~mm})$, and the average navicular drop in the pronated foot group is $12.66 \mathrm{~mm}$, which is in the abnormal range (more than $10 \mathrm{~mm}$ ) [34]. The difference in the navicular drop between the two groups is statistically significant $(\mathrm{P}<0.001)$.

The results of this study can help therapists and coaches choose the right therapeutic and training approach. In the case of the former, identifying the anomalies and the associated injuries could be leveraged to better gear the therapeutic exercises to cure the individuals. Additionally, coaches may implement balance-related training programs to improve the performance of athletes with foot pronation.

This study had several limitations, most notably the absence of a study of kinematic ankle joints. Also, in this study, only male subjects were studied. Considering the different anatomy and biomechanical behavior of women and men, women should also be examined in comparison with men.

\section{Conclusion}

According to the results of the current research, it seems that pronated foot is a factor affecting the biomechanics of the landing movement that changes the postural control of the body in the medial-lateral direction and also a change in the onset time of medial gastrocnemius, soleus, tibialis anterior, and peroneus longus muscles activities. Given the shift in the postural control of the body in the medial-lateral direction and the onset time of the ankle muscles activity in people with foot pronation, it seems that the combination of landing motion with the lower extremities abnormalities, especially in ankle, can make a person vulnerable to injury. The results of the research call for an accurate and comprehensive study of the effect of the abnormal structure of foot on the function of lower extremities during landing motion to design an appropriate training program.

\section{Ethical Considerations}

\section{Compliance with ethical guidelines}

All ethical principles were considered in this article.

\section{Funding}

This research did not receive any specific grant from funding agencies in the public, commercial, or not-forprofit sectors.

\section{Authors contributions}

All authors contributed in preparing this article.

Conflict of interest

The authors declared no conflict of interest.

\section{References}

[1] Lin CJ, Lai KA, Kuan TS, Chou YL. Correlating factors and clinical significance of flexible flatfoot in preschool children. Pediatric Orthopedics. 2001; 21(3): 378-82. [DOI:10.1097/00004694-200105000-00022]

[2] Jafarnezhadgero A, Shad MM, \& Ferber R. The effect of foot orthoses on joint moment asymmetry in male children with flexible flat feet. Journal of Bodywork and Movement Therapies. 2018; 22(1):83-89. [DOI:10.1016/j.jbmt.2017.04.007] [PMID]

[3] Martinez A, Gijón-Noguerón G, Alfageme P, Montes J, Evans M. Foot posture development in children aged 5 to 11 years: A 
three-year prospective study. Gait \& Posture. 2018; 62:280-284. [DOI:10.1016/j.gaitpost.2018.03.032] [PMID]

[4] Van Boerum DH, Sangeorzan BJ. Biomechanics and pathophysiology of flat foot. Foot and Ankle Clinics. 2003; 8(3):419-30. [DOI:10.1016/S1083-7515(03)00084-6]

[5] Lee MS, Vanore JV, Thomas JL, Catanzariti AR, Kogler G, Kravitz SR, et al. Diagnosis and treatment of adult flatfoot. Foot and Ankle Surgery. 2005; 44(2):113-78. [DOI:10.1053/j.jfas.2004.12.001] [PMID]

[6] Menz HB, Morris ME, Lord SR. Foot and ankle characteristics associated with impaired balance and functional ability in older people. The Journals of Gerontology Series A Biological Sciences and Medical Sciences. 2005; 60(12):1546-52. [DOI:10.1093/gerona/60.12.1546] [PMID]

[7] Williams Iii DS, McClay IS, Hamill J. Arch structure and injury patterns in runners. Clinical Biomechanics 2001; 16(4):341-7. [DOI:10.1016/S0268-0033(01)00005-5]

[8] Mashhadi M. Foot arch index during Jana's Short-Foot maneuver in subjects with excessively pronated feet. Medicina Sportiva: Journal of Romanian Sports Medicine Society. 2017; 13(2):2935-39.

[9] Hunt AE, Smith RM. Mechanics and control of the flat versus normal foot during the stance phase of walking. Clinical Biomechanics. 2004; 19(4):391-7. [DOI:10.1016/j.clinbiomech.2003.12.010] [PMID]

[10] Cote KP, Brunet ME, II BMG, Shultz SJ. Effects of pronated and supinated foot postures on static and dynamic postural stability. Athletic Training. 2005; 40(1):41-8.

[11] Cowley HR, Ford KR, Myer GD, Kernozek TW, Hewett TE. Differences in neuromuscular strategies between landing and cutting tasks in female basketball and soccer athletes. Journal of Athletic Training. 2006; 41(1):67-73.

[12] Robertson G, Caldwell G, Hamill J, Kamen G, Whittlesey S. Research methods in biomechanics. Champaign: Human Kinetics; 2013.

[13] Determan JJ, Frederick EC, Cox JS, Nevitt MN. High impact forces in skateboarding landings affected by landing outcome. Footwear Science. 2010; 2(3):159-70. [DOI:10.1080 /19424280.2010.525534]

[14] Coventry E, O'Connor KM, Hart BA, Earl JE, Ebersole KT. The effect of lower extremity fatigue on shock attenuation during single-leg landing. Clin Biomech. 2006; 21(10):1090-7. [DOI:10.1016/j.clinbiomech.2006.07.004] [PMID]

[15] Sung PS. The ground reaction force thresholds for detecting postural stability in participants with and without flat foot. Biomechanics. 2015; 49(1):60-5. [DOI:10.1016/j.jbiomech.2015.11.004] [PMID]

[16] Kim JA, Lim OB, Yi CH. Difference in static and dynamic stability between flexible flatfeet and neutral feet. Gait and Posture. 2015; 41(2):546-50. [DOI:10.1016/j.gaitpost.2014.12.012] [PMID]

[17] Colby SM, Hintermeister RA, Torry MR, Steadman JR, Malone TR, Colby SM, et al. Author response. Journal of Orthopaedic and Sports Physical Therapy. 1999; 29(8):444-54. [DOI:10.2519/ jospt.1999.29.8.444] [PMID]

[18] Gray EG, Basmajian JV. Electromyography and cinematography of leg and foot (normal and flat) during walking.
The Anatomical Record. 1968; 161(3):1-15. [DOI:10.1002/ ar.1091610101] [PMID]

[19] Williams GN, Barrance PJ, Snyder-Mackler L, Axe MJ, Buchanan TS. Specificity of muscle action after anterior cruciate ligament injury. Journal of Orthopedics Researching. 2003; 21(6):1131-7. [DOI:10.1016/S0736-0266(03)00106-2]

[20] Khodaveisi H, Sadeghi H, Memar R, Anbarian M. Comparison of selected muscular activity of trunk and lower extremities in young women's walking on supinated, pronated and normal foot. Apunts Medicina De l'Esport. 2016; 19(6):262-8. [DOI:10.1016/j. apunts.2015.10.002]

[21] Ilbeigi S, Noorollah Gh, Hoseinzade E. "The comparison of shank muscles electrical activity in people with flat and normal feet during walking on treadmill with different speeds". Razi Journal of Medical Sciences 2018; 25:21-29.

[22] Evans AM, Copper AW, Scharfbillig RW, Scutter SD, Williams MT. Reliability of the foot posture index and traditional measures of foot position. Journal of the American Podiatric Medical Association. 2003; 93(3):203-13. [DOI:10.7547/87507315-93-3-203] [PMID]

[23] Redmond AC, Crosbie J, Ouvrier RA. Development and validation of a novel rating system for scoring standing foot posture: the Foot posture index. Clin Biomech. 2006; 21:89-98. [DOI:10.1016/j. clinbiomech.2005.08.002] [PMID]

[24] Hermens DH, \& Feriks B. Surface Electromyograghy for the Non-Invasive Assessment of Muscle (SENIAM) [Internet]. 2005 [Cited 2005 Des 8]. Available from: http:/ / www.SENIAM.com/.

[25] Zazulak BT, Ponce PL, Straub SJ, Medvecky MJ, Avedisian L, \& Hewett TE. Gender comparison of hip muscle activity during single-leg landing. Journal of Orthopaedic and Sports Physical Therapy 2005; 35(5):292-9. [DOI:10.2519/jospt.2005.35.5.292] [PMID]

[26] Winter DA. Biomechanics and motor control of human movement. New Jersey, United States: John Wiley \& Sons; 2009. [DOI:10.1002/9780470549148]

[27] De Cock A, Vanrenterghem J, Willems T, Witvrouw E, De Clercq D. The trajectory of the centre of pressure during barefoot running as a potential measure for foot function. Gait and Posture 2008; 27(4):669-75. [DOI:10.1016/j.gaitpost.2007.08.013] [PMID]

[28] Sokhanguee Y, Sokhanguee M. Flat foot. Tehran: Harkat Now; 2006.

[29] Javdaneh N, Minoonejad H, Shirzad E, Javdaneh N. [The Investigation of the Muscle Timing of Anterior Cruciate Ligament agonist and antagonist muscles in athletes with hyper pronated feet (Persian)]. Journal of Military Medicine. 2016; 17(4):257-264

[30] Bryan L, Riemann, Scott M, Lephart? The sensorimotor system, Part II: The role of proprioception in motor control and functional joint stability. Journal of Athletic Training. 2002; 37(1):80-4.

[31] Samadi H. [Effect of neuromascular training on electromyographic characters of ankle muscles and stability perception in male athlete with functional ankle instability (Persian)]. [PhD. thesis]. Tehran: University of Tehran; 2013.

[32] Hagen M, Schwiertz G, Landorf KB, Menz HB, Murley GS. Selective activation of lower leg muscles during maximum voluntary isometric contractions. Human Movement Science. 2016: 50:30-7. [DOI:10.1016/j.humov.2016.10.002] [PMID] 
[33] De Baets L, Van Deun S, Monari D, Jaspers E. Three-dimensional kinematics of the scapula and trunk, and associated scapular muscle timing in individuals with stroke. Human Movement Science. 2016; 48:82-90. [DOI:10.1016/j.humov.2016.04.009] [PMID]

[34] Cote KP, Brunet BMG, Shultz SJ. Effects of pronated and supinated foot postures on static and dynamic postural stability. Athletic Training. 2005; 40(1):41. 